\title{
Light and Gravity Effects on Adenine Nucleotide Content and Energy Charge in Maize Roots
}

\author{
Reinhard Gabathuler and Paul-Emile Pilet \\ Institute of Plant Biology and Physiology of the University, \\ 1005 Lausanne, 6 Pl. de la Riponne, Switzerland
}

\begin{abstract}
Two millimeter apical segments of maize (cv. LG 11 ) primary roots were analysed in relation to the effects of light and gravity on adenine nucleotide content. Adenosine triphosphate (ATP) content is very sensitive to these stimuli. ATP levels are lower in roots exposed to light than in those kept in the dark. The energy charge (E.C.) decreases markedly after exposure to light and gravity. For the vertical roots E.C. is stable. Present data confirm the fact that light and gravity may act on cell metabolism, modifying the energy requirements. This will be discussed in relation to some hormone actions.

Key words: Adenine nucleotides - Energy charge - Gravity effect - Light effect - Root (maize) - Zea mays.
\end{abstract}

Problems related to root growth and gravireaction have recently been reviewed (Audus 1975, Juniper 1976, Pilet 1977, Wilkins 1979). These two processes are under the influence of certain growth inhibiting substances produced or released by the root cap in response to gravity (Gibbons and Wilkins 1970, Pilet 1971, 1972, 1977, 1980, Wilkins 1979) and to light (Pilet 1973, 1975, 1976, 1978, Wilkins and Wain 1974, 1975).

The interaction between several endogenous growth regulators (acropetal and basipetal flows) (Pilet 1975, 1977, 1979), which reach the elongation zone, could play an essential part in the growth and gravitropism which occur under light and gravitational stimulation (Beffa and Pilet, in press, Ney and Pilet 1980).

The relationship between the growth of cells and their endogenous adenine nucleotide content was previously analysed in maize root segments (Marrè and Forti 1958). The gravi- and light-reactivity of the maize roots is correlated with a high level of ATP inside their growing and gravireacting parts, this was studied on two maize cultivars (ANJOU and ORLA) (Pilet et al. 1978, Steck and Pilet 1979). The importance of the energy charge [E.C. $=1 / 2(2 \mathrm{ATP}+\mathrm{ADP}) /(\mathrm{ATP}+\mathrm{ADP}+$ AMP)] was demonstrated in the regulation of the enzyme activities (Atkinson and Walton 1967). The growth properties of both vertical and gravireacting roots can be correlated to the quantity of $\mathrm{O}_{2}$ absorption (Bejaoui and Pilet 1977). The root tip was found to be the most sensitive part of the root in relation to the effect of light on the ATP content (Pilet et al. 1978).

The aim of the present paper is to evaluate the effects of light and gravity on the

Abbreviation: E.C., energy charge. 
adenine nucleotide (ATP, ADP and AMP) content and E.C. in maize roots. The time course of these variations is reported and discussed.

\section{Materials and Methods}

Caryopses of Zea mays L. cv. LG 11 (Ass. Suisse des Sélection., Lausanne) were used. The conditions for preparing the maize fruits have been previously described (Pilet 1977). Selected caryopses were first soaked in flowing tap water $(24 \mathrm{hr})$, prior to germination, between sheets of moist filter paper, in darkness $\left(19 \pm 1^{\circ} \mathrm{C}\right)$. When primary roots-which grew vertically-reached $15 \pm 3 \mathrm{~mm}$ in length, they were selected in green light (Fluorescent light with filters: $530 \pm 20 \mathrm{~nm}, 1.2 \mu \mathrm{W}$ $\mathrm{cm}^{-2}$ at the root level) and mounted-being intact and still attached to their caryopses - on plastic frames. The frames were then placed in closed boxes $\left(19 \pm 1^{\circ} \mathrm{C}\right)$ in which a humid atmosphere $(90 \pm 5 \%)$ was maintained. For the light experiments, plants were immediately brought under white fluorescent light (Philips $8 \mathrm{~W} / 33$, $26 \mu \mathrm{W} / \mathrm{cm}^{2}$ ) (Pilet 1979).

Root segments, from 0 to $2 \mathrm{~mm}$, were cut and rapidly frozen in liquid nitrogen. Ten lyophilised segments were ground then completed with $7 \mathrm{ml}$ boiling TRIS buffer $\mathrm{pH} 7.4$ (containing $\mathrm{MgSO}_{4}, \mathrm{~K}_{2} \mathrm{SO}_{4}$ and EDTA) (Pilet et al. 1978, Steck and Pilet 1979, Wagner et al. 1974). The extraction was performed for $10 \mathrm{~min}$. Extracts were then immediately frozen and kept at $-25^{\circ} \mathrm{C}$ until the nucleotides were tested. ATP was assayed by injecting automatically (Fisons Diluter type LFA-20) $50 \mu \mathrm{l}$ of firefly extract (FLE-250 or FLE-50, Sigma Chemical Co.) and $850 \mu 1$ buffer (41.7 mм TRIS, $3.5 \mathrm{~mm} \mathrm{MgSO}_{4}, 0.6 \mathrm{~mm}$ EDTA) into $100 \mu \mathrm{l}$ extract. The light produced by the reaction was measured for $10 \mathrm{sec}$ using a Bioluminescence Photometer XP-2000 (SKAN, Basel) coupled to a digital integrator. ADP and AMP were estimated after they had been converted to ATP by incubating the extracts with pyruvate kinase (in the presence of phosphoenol pyruvate) and adenylate kinase (Pradet 1967). The E.C. was then calculated. E.C. is linearly related to the amount of metabolically available energy that is momentarily stored in the adenylate system.

Table 1 AMP (in nmoles \pm standard deviation) in relation to time (in min) of apical root segments $(0-2 \mathrm{~mm}$ ) prepared from maize (cv. LG 11) primary roots vertically and horizontally placed in darkness and in light

\begin{tabular}{cccccc}
\hline \multirow{2}{*}{$\begin{array}{c}\text { Time } \\
(\mathrm{min})\end{array}$} & \multicolumn{2}{c}{ Vertical position } & & \multicolumn{2}{c}{ Horizontal position } \\
\cline { 2 - 3 } \cline { 5 - 6 } & Dark & Light & & Dark & Light \\
\hline 0 & $0.420 \pm 0.02$ & $0.420 \pm 0.02$ & & $0.420 \pm 0.02$ & $0.420 \pm 0.02$ \\
20 & $0.557 \pm 0.02$ & $0.510 \pm 0.03$ & & $0.493 \pm 0.03$ & $0.490 \pm 0.02$ \\
40 & $0.512 \pm 0.04$ & $0.544 \pm 0.03$ & & $0.584 \pm 0.03$ & $0.508 \pm 0.02$ \\
60 & $0.511 \pm 0.02$ & $0.522 \pm 0.02$ & & $0.564 \pm 0.03$ & \\
80 & $0.529 \pm 0.02$ & $0.701 \pm 0.04$ & & $0.572 \pm 0.06$ & \\
100 & $0.518 \pm 0.02$ & $0.656 \pm 0.06$ & & $0.510 \pm 0.03$ & $0.490 \pm 0.04$ \\
120 & $0.556 \pm 0.03$ & $0.682 \pm 0.06$ & & $0.676 \pm 0.02$ & $0.540 \pm 0.02$ \\
& & & & &
\end{tabular}

For each mean value, 50 roots were used and the assays were repeated 5 times. 
Table $2 \Sigma=$ ATP + ADP + AMP (in nmoles \pm standard deviation) in relation to time (in min) of apical root segments $(0-2 \mathrm{~mm})$ prepared from maize (cv. LG 11) primary roots vertically and horizontally placed in darkness and in light

\begin{tabular}{cccccc}
\hline \multirow{2}{*}{$\begin{array}{c}\text { Time } \\
(\mathrm{min})\end{array}$} & \multicolumn{2}{c}{ Vertical position } & & \multicolumn{2}{c}{ Horizontal position } \\
\cline { 2 - 3 } \cline { 5 - 6 } & Dark & Light & & Dark & Light \\
\hline 0 & $1.449 \pm 0.05$ & $1.449 \pm 0.05$ & & $1.449 \pm 0.05$ & $1.449 \pm 0.05$ \\
20 & $1.713 \pm 0.03$ & $1.622 \pm 0.04$ & & $1.569 \pm 0.05$ & $1.685 \pm 0.04$ \\
40 & $1.652 \pm 0.06$ & $1.686 \pm 0.04$ & & $1.809 \pm 0.08$ & $1.595 \pm 0.05$ \\
60 & $1.780 \pm 0.03$ & $1.636 \pm 0.03$ & & $1.726 \pm 0.02$ & \\
80 & $1.729 \pm 0.05$ & $1.735 \pm 0.05$ & & $1.652 \pm 0.03$ & $1.554 \pm 0.04$ \\
100 & $1.719 \pm 0.02$ & $1.764 \pm 0.06$ & & $1.643 \pm 0.01$ & $1.529 \pm 0.05$ \\
120 & $1.736 \pm 0.04$ & $1.655 \pm 0.06$ & & $1.825 \pm 0.04$ & $1.654 \pm 0.03$ \\
& & & &
\end{tabular}

For each mean value, 50 roots were used and the assays were repeated 5 times.

\section{Results}

In a first series of assays, the roots were kept in vertical position in the dark. As can be seen in Fig. 1A, the ATP content increases with AMP content (Table 1) and with the pool of adenine nucleotides (Table 2) during the first hour of measurement. These data clearly indicate that when roots are transferred to new conditions, a period of adaptation is required (Beffa and Pilet, in press). In darkness, the ATP content in vertical roots increased to reach a steady state (Fig. IA) after $20 \mathrm{~min}$. For horizontal roots, a steady state develops with a lower equilibrium level of ATP (Fig. 1B). In darkness, when roots were horizontal, different kinetics were observed in relation to adenine nucleotide levels compared with that associated with the vertical position. This is marked with a peak of ATP after $40 \mathrm{~min}$. After that time, a decrease in ATP content to a steady state of $0.85 \mathrm{nmol} /$ segment can be observed (Fig. 1B). In the vertical position, after $20 \mathrm{~min}$, this value is of about $0.9 \mathrm{nmol}$ ATP per segment (Fig. 1A).

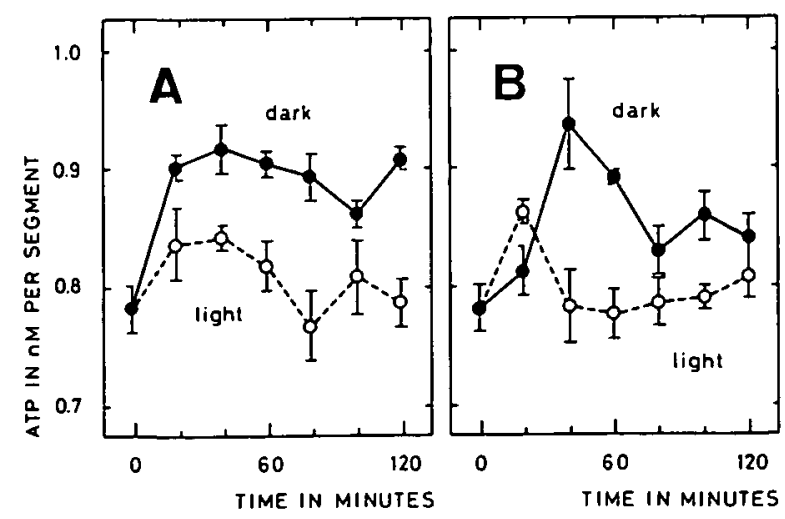

Fig. 1 ATP (in nmoles \pm standard deviation) in relation to time (in $\mathrm{min}$ ) of apical root segments (0-2 mm) prepared from maize (cv. LG 11) primary roots vertically (A) or horizontally (B) placed in darkness or in light. For each mean value, 50 roots were used and the assays were repeated 5 times. 
Table 3 ADP (in nmoles \pm standard deviation) in relation to time (in min) of apical root segments $(0-2 \mathrm{~mm})$ prepared from maize (cv. LG 11) primary roots vertically and horizontally placed in darkness and in light

\begin{tabular}{|c|c|c|c|c|}
\hline \multirow{2}{*}{$\begin{array}{l}\text { Time } \\
\text { (min) }\end{array}$} & \multicolumn{2}{|c|}{ Vertical position } & \multicolumn{2}{|c|}{ Horizontal position } \\
\hline & Dark & Light & Dark & Light \\
\hline 0 & $0.245 \pm 0.01$ & $0.245 \pm 0.01$ & $0.245 \pm 0.01$ & $0.245 \pm 0.01$ \\
\hline 20 & $0.253 \pm 0.01$ & $0.315 \pm 0.01$ & $0.262 \pm 0.03$ & $0.293 \pm 0.01$ \\
\hline 40 & $0.223 \pm 0.01$ & $0.300 \pm 0.01$ & $0.288 \pm 0.03$ & $0.303 \pm 0.01$ \\
\hline 60 & $0.365 \pm 0.02$ & $0.269 \pm 0.01$ & $0.271 \pm 0.01$ & $0.277 \pm 0.01$ \\
\hline 80 & $0.307 \pm 0.02$ & $0.324 \pm 0.02$ & $0.250 \pm 0.01$ & $0.302 \pm 0.01$ \\
\hline 100 & $0.366 \pm 0.01$ & $0.298 \pm 0.01$ & $0.274 \pm 0.01$ & $0.308 \pm 0.01$ \\
\hline 120 & $0.279 \pm 0.02$ & $0.253 \pm 0.01$ & $0.307 \pm 0.01$ & $0.301 \pm 0.02$ \\
\hline
\end{tabular}

For each mean value, 50 roots were used and the assays were repeated 5 times.

Light exposed roots generally show a decrease in ATP levels (Fig. 1A and 1B) and an increase of ADP (Table 3) compared with control roots kept in darkness. In the vertical position, the ATP level is significantly lower after $20 \mathrm{~min}$ in light which has a very rapid effect on the E.C. for vertical roots: E.C. decreases very rapidly. With horizontal roots, after switching on the light (Fig. 1B), a maximum in the ATP level is immediately noted. The maximal content of ATP is less than that obtained in the dark. However, the light treatment displaces the ATP peak which appears 20 min earlier than is found for the control dark treatment. After $40 \mathrm{~min}$, the ATP level returned to its initial value (Fig. 1B). For horizontal, dark grown roots, initially the ADP contents increase more slowly, but with larger variability (Table 3). AMP (Table 1) and the pool of adenine nucleotides (Table 2) generally increase during the time course of the experiments. They contribute finally to the decrease in the energy charge as reported in Fig. 2A and 2B.

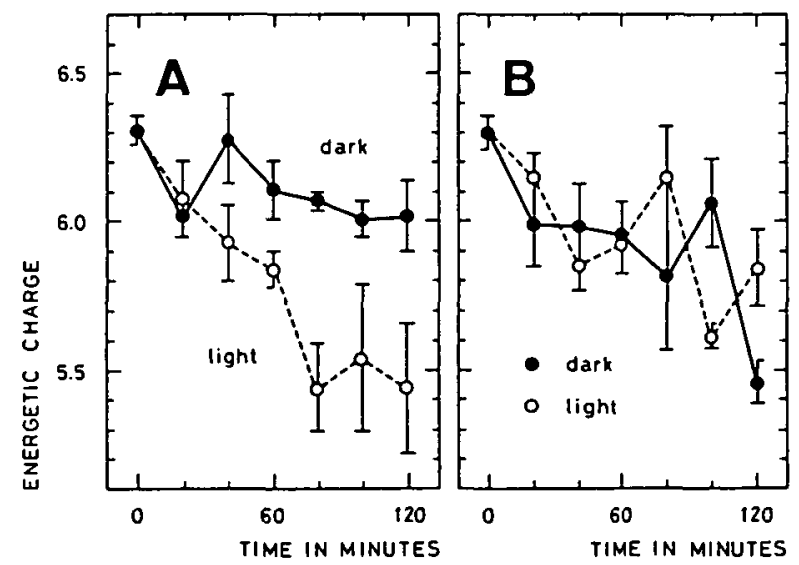

Fig. 2 Energy charge $[$ E.C. $=1 / 2(2 \mathrm{ATP}+\mathrm{ADP}) /(\mathrm{ATP}+\mathrm{ADP}+\mathrm{AMP})]$ in relation to time (in $\mathrm{min}$ ) of apical root segments $(0-2 \mathrm{~mm}$ ) prepared from maize (cv. LG 11) primary roots vertically (A) or horizontally (B) placed in darkness and in light. For each mean value, 50 roots were used and the assays were repeated 5 times. 
Light appears to have a larger effect on vertical roots than on horizontal ones. In vertical roots, change in ATP levels in the first $2 \mathrm{hr}$ (Fig. 1A) is always depressed. Whereas in horizontal roots, the adenine nucleotide contents show real qualitative differences in light and dark treated roots (Fig. 1B), particularly in relation to the kinetics of steady-state development.

A typical situation is found when the E.C. values are compared in light/dark treatments for roots of horizontal and vertical orientations. As can be seen in Fig. $2 \mathrm{~A}$ and $2 \mathrm{~B}$, no significant differences may be noted in the E.C. for light and dark treatments for horizontally oriented roots. However, for vertical roots, light treatment induces a very rapid (latent period: $20 \mathrm{~min}$ ) change in E.C. values: the consistently lower E.C. data being for the light treated roots.

\section{Discussion}

Elongation and gravireaction at least of maize roots, in light and in the dark, are controlled by some growth inhibitors (Pilet 1976, 1977, 1979, Wilkins and Wain 1974, Wilkins 1979). Light and gravity perception is essentially located in the root cap (Barlow 1974, Juniper 1976, Pilet and Ney 1978, Wilkins and Wain 1974), which is the source of some growth inhibiting factors. They are basipetally transported to the elongation zone of the root in which they regulate the cell extension (Pilet 1973, 1977, Shaw and Wilkins 1973). The graviresponse may be induced or stimulated by white light (Pilet 1975, 1976, 1979, Wilkins and Wain 1974). Using GC/MS technique, IAA (Rivier and Pilet 1974) and ABA (Pilet and Rivier 1980) have been found in maize root tips, light exposed roots containing more ABA than those kept in darkness. The IAA moves preferentially in the acropetal direction through maize roots (Pilet 1964, 1975, Scott and Wilkins 1968) and is certainly involved in the regulation of root elongation (Audus 1975, Elliott 1975, 1977, Pilet 1975, Pilet et al. 1979).

What is the possible relation between the light effect on growth inhibitors and the energy metabolism parameters (i.e. ATP, E.C., ...)? It has been found that light very rapidly affects the adenine nucleotide content in root tips. The ATP level decreases while ADP and AMP content increases; light acts on the E.C., decreasing it in comparison with that in the dark. This is observed in vertical and to a lesser extent in horizontal position. Formation (or release) of ABA, as well as other endogenous growth inhibiting substances (Pilet 1977, 1979) may be stimulated by light inside the cap cells. These rapid changes in F.C. could reflect the energy utilised in directing growth regulator transport in the first minutes after illumination. Clearly, in the longer term, this situation is complicated by a net synthesis of ABA (Pilet and Rivier 1980) in the root cap. The precise link between photoreception and changes in energetic metabolism remains unclear, although some results on phytochrome mediated ATPase activity (De Greef et al. 1976) may offer a possible explanation. When comparing data in Fig. $2 \mathrm{~A}$ and $2 \mathrm{~B}$, it has to be noted that there are different responses for horizontal and vertical roots in light. It cannot be ruled out that horizontally placed roots are less sensitive, although such light regulated parameters as $\mathrm{ABA}$ accumulation were not affected by orientation with respect to gravity (Pilet and Rivier 1981). If the relative growth of these roots in horizontal and vertical positions is considered (Beffa and Pilet, in press), it is clear that E.C. 
does not always show a clear correlation with growth capacity, particularly when the root is gravistimulated. Some photosensitive pigments have been found in root tips (Klemmer and Schneider 1979, Tepfer and Bonnett 1972). Gravistimulation by light can be largely reverted by far red light given after a stimulus (Klemmer and Schneider 1979). Four minutes after the exposure of mung bean secondary root tips to red light, a reduction in ATP content of the tissues was recorded (Yunghans and Jaffe 1970). IAA may have some indirect effects on ATPases as it stimulates proton extrusion in a variety of auxin sensitive tissues (Cleland 1975, Marrè et al. 1975, Rayle and Cleland 1980). ABA affects the ion transport and the water permeability of roots (Behl and Jeschke 1979, Pitman and Cram 1973). These effects, frequently associated to these growth regulators, are more pronounced in light: the photosensitive pigments may play a role in the modulation of the action of growth hormones and, consequently, they may have direct or indirect effect, through growth regulators, on adenine nucleotide content of roots.

The authors are grateful to Dr. M. M. Moloney for helpful discussions.

\section{References}

Atkinson, D. E. and G. M. Walton (1967) Adenosine triphosphate conservation in metabolic regulation. J. Biol. Chem. 242: 3239-3241.

Atkinson, D. E. (1968) The energy charge of the adenylate pool as a regulatory parameter. Interaction with feedback modifiers. Biochemistry 7: 4030-4034.

Audus, L. J. (1975) Geotropism in roots. In The Development and Function of Roots. Edited by J. G. Torrey and D. T. Clarkson. p. 327-363. Academic Press, New York.

Barlow, P. W. (1974) Recovery of geotropism after removal of the root cap. J. Exp. Bot. 25: 11371146.

Behl, R. and W. D. Jeschke (1979) On the action of abscisic acid on transport, accumulation and uptake of $\mathrm{K}^{+}$and $\mathrm{Na}^{+}$in excised barley roots; effects of the accompanying anions. Z. Pflanzenphysiol. 95: 335-353.

Bachler, W. and P. E. Pilet (1981) Kinetics analysis of root growth and georeaction. Physiol. Plant. $51: 27-32$.

Bejaoui, M. and P. E. Pilet (1977) Oxygen uptake of growing and geostimulated roots. Plant Sci. Lett. 8: 223-226.

Beffa, R. and P. E. Pilet (1981) Elongation and gravireaction of intact and segmented roots: Light effects. Physiol. Plant. (in press).

Cleland, R. E. (1975) Auxin induced hydrogen ion excretion: Correlations with growth and control by external $\mathrm{pH}$ and water stress. Planta $127: 233-242$.

De Greef, J. A., R. Caubergs, J. P. Verbelen and E. Moereels (1976) Phytochrome mediated interorgan dependence and rapid transmission of the light stimulus. In Light and Plant Development. Edited by H. Smith. p. 295-316. Butterworth, London.

Elliott, M. C. (1975) Hormone interactions in regulation of root growth and geotropism. Plant Physiol. 56S: 39.

Elliott, M. C. (1977) Auxin and the regulation of root growth. In Plant Growth Regulation. Edited by P. E. Pilet. p. 100-108. Springer Verlag, Berlin.

Gibbons, G. S. B. and M. B. Wilkins (1970) Growth inhibitor production by root caps in relation to geotropic responses. Nature 226: 558-559.

Juniper, B. E. (1976) Geotropism. Ann. Rev. Plant Physiol. 27: 385-406.

Klemmer, R. and H. A. W. Schneider (1979) On a blue light effect and phytochrome in the stimulation of georesponsiveness of maize roots. Z. Pfianzenphysiol. 95: 189-197. 
Marrè, E. and G. Forti (1958) Metabolic responses to auxin III. The effect of auxin on ATP level as related to the auxin induced respiration increase. Physiol. Plant. 11:36-47.

Marrè, E., P. Lado, F. Rasi-Caldogno, R. Colombo, M. Cocucci and M. I. De Michelis (1975) Regulation of proton extrusion by plant hormones and cell elongation. Physiol. Vég. 13: 797-811.

Ney, D. and P. E. Pilet (1980) Importance of caryopsis in root growth and georeaction. Physiol. Plant. 50: 166-168.

Pilet, P. E. (1964) Auxin transport in roots. Nature 204: 561-562.

Pilet, P. E. (1971) Root cap and georeaction. Nature 233: 115-116.

Pilet, P. E. (1972) Root cap and root growth. Planta 106: 169-171.

Pilet, P. E. (1973) Inhibiteur de croissance et énergie lumineuse. C. R. Acad. Sci. Paris 276: 25292531.

Pilet, P. E. (1975) Effects of light on the georeaction and growth inhibitor content of roots. Physiol. Plant. 33: 94-97.

Pilet, P. E. (1975) Abscisic acid as a root inhibitor: physiological analyses. Planta 122: 299-302.

Pilet, P. E. (1976) The light effect on the growth inhibitors produced by the root cap. Planta 130: 245-249.

Pilet, P. E. (1977) Growth inhibitors in growing and geostimulated maize roots. In Plant Growth Regulation. Edited by P. E. Pilet. p. 115-128. Springer Verlag, Bcrlin.

Pilet, P. E. (1978) The role of the cap in the geotropism of roots exposed to light. Z. Pfanzenphysiol. 89: $411-426$.

Pilet, P. E. (1979) Kinetics of the light-induced georeactivity of maize roots. Planta 145: 403-404.

Pilet, P. E. (1980) Hormonal control of root elongation: some light effects. In Plant Growth Substances. Edited by F. Skoog. p. 450-461. Springer Verlag, Berlin.

Pilet, P. E., P. Steck and G. Mayor (1978) ATP in growing roots: georeaction and light effect. Plant Sci. Lett. 12: 343-347.

Pilet, P. E. and D. Ney (1978) Rapid, localized light effect on root growth in maize. Planta 144: $109-110$.

Pilet, P. E., M. C. Elliott and M. M. Moloney (1979) Endogenous and exogenous auxin in the control of root growth. Planta 146: 405-408.

Pilet, P. E. and L. Rivier (1980) Light and dark georeaction of maize roots: effect and endogenous level of abscisic acid. Plant Sci. Lett. 18: 201-206.

Pilet, P. E. and L. Rivier (1981) Abscisic acid distribution in horizontal maize root segments. Planta (in press).

Pitman, M. G. and W. J. Cram (1973) Ion Transport in Plants. Edited by W. P. Anderson. Academic Press, London.

Pradet, A. (1967) Etude des adénosine-5'-mono, di, triphosphates dans les tissues végétaux I: Dosage enzymatique. Physiol. Vég. 5: 209-221.

Rayle, D. L. and R. E. Cleland (1980) Evidence that auxin-induced growth of soybean hypocotyls involves proton excretion. Plant Physiol. 66: 433-437.

Rivier, L. and P. E. Pilet (1974) Indolyl-3-acetic acid in cap and apex of maize roots: identification and quantification by mass fragmentography. Planta 120: 107-112.

Scott, T. K. and M. B. Wilkins (1968) Auxin transport in roots II. Polar fluxes of IAA in Zea roots. Planta 83: 323-334.

Shaw, S. and M. B. Wilkins (1973) The source and lateral transport of growth inhibitors in geotropically stimulated roots of Zea mays and Pisum sativum. Planta 109: 11-26.

Steck, P. and P. E. Pilet (1979) Effect of light on adenine nucleotide content of georeacting maize roots. Plant E Cell Physiol. 20: 413-421.

Tepfer, D. A. and H. T. Bonnett (1972) The role of phytochrome in the geotropic behaviour of roots of Convulvulus arvensis. Planta 106: 311-324.

Wagner, E., J. Tetzner, U. Haertlé and G. F. Deitzer (1974) Endogenous rhythmicity and energy transduction VIII. Kinetics in enzyme activity, redox state and energy charge as related to photomorphogenesis in seedlings of Chenopodium rubrum L. Ber. Deutsch. Bot. Ges. 87: 291-302. 
Wilkins, H. and R. L. Wain (1974) The root cap and control of root elongation in Zea mays L. seedlings exposed to white light. Planta $121: 1-8$.

Wilkins, H. and R. L. Wain (1975) The role of root cap in the response of the primary roots of Zea mays L. seedlings to white light and to gravity. Planta 123: 217-222.

Wilkins, M. B. (1979) Growth control mechanism in gravitropism. In Encyclopedia of Plant Physiology, New Series 7, Physiology of Movements. Edited by W. Haupt and M. E. Feinleib. p. 601626. Springer Verlag, Berlin.

Yunghans, H. and M. J. Jaffe (1970) Phytochrome controlled adhesion of mung bean root tips to glass: a detailed characterization of the phenomena. Physiol. Plant. 23: 1004-1016.

(Received June 23, 1981; Accepted September 25, 1981) 